\title{
Everolimus in Neuroendocrine Tumors of the Gastrointestinal Tract and Unknown Primary
}

DOI:

$10.1159 / 000477585$

Document Version

Accepted author manuscript

Link to publication record in Manchester Research Explorer

\section{Citation for published version (APA):}

Singh, S., Carnaghi, C., Buzzoni, R., Pommier, R. F., Raderer, M., Tomasek, J., Lahner, H., Valle, J. W., Voi, M., Bubuteishvili-pacaud, L., Lincy, J., Wolin, E., Okita, N., Libutti, S. K., Oh, D., Kulke, M., Strosberg, J., Yao, J. C., Pavel, M. E., \& Fazio, N. (2018). Everolimus in Neuroendocrine Tumors of the Gastrointestinal Tract and Unknown Primary. Neuroendocrinology, 106(3), 211-220. https://doi.org/10.1159/000477585

Published in:

Neuroendocrinology

\section{Citing this paper}

Please note that where the full-text provided on Manchester Research Explorer is the Author Accepted Manuscript or Proof version this may differ from the final Published version. If citing, it is advised that you check and use the publisher's definitive version.

\section{General rights}

Copyright and moral rights for the publications made accessible in the Research Explorer are retained by the authors and/or other copyright owners and it is a condition of accessing publications that users recognise and abide by the legal requirements associated with these rights.

\section{Takedown policy}

If you believe that this document breaches copyright please refer to the University of Manchester's Takedown Procedures [http://man.ac.uk/04Y6Bo] or contact uml.scholarlycommunications@manchester.ac.uk providing relevant details, so we can investigate your claim.

\section{OPEN ACCESS}


Everolimus in Neuroendocrine Tumors of the Gastrointestinal Tract and Unknown Primary

Simron Singh, $\mathrm{MD}^{1}$, Carlo Carnaghi, $\mathrm{MD}^{2}$, Roberto Buzzoni, $\mathrm{MD}^{3}$, Rodney F. Pommier, $\mathrm{MD}^{4}$, Markus Raderer, $\mathrm{MD}^{5}$, Jiri Tomasek, $\mathrm{PhD}^{6}$, Harald Lahner, $\mathrm{MD}^{7}$, Juan W. Valle, $\mathrm{MB}^{8}$, Maurizio Voi, $\mathrm{MD}^{9}$, Lida Bubuteishvili-Pacaud, $\mathrm{MD}^{10}$, Jeremie Lincy, $\mathrm{PhD}^{10}$, Edward Wolin, $\mathrm{MD}^{11}$, Natsuko Okita, $\mathrm{MD}^{12}$, Steven K. Libutti, MD ${ }^{11}$, Do-Youn Oh, MD, $\mathrm{PhD}^{13}$, Matthew Kulke, $\mathrm{MD}^{14}$, Jonathan Strosberg, $\mathrm{MD}^{15}$, James C. Yao, $\mathrm{MD}^{16}$, Marianne E. Pavel, $\mathrm{MD}^{17}$, Nicola Fazio, $\mathrm{MD}, \mathrm{PhD}^{18}$ for the RAD001 in Advanced Neuroendocrine Tumors, Fourth Trial (RADIANT-4) Study Group

${ }^{1}$ Sunnybrook Health Sciences Centre, Toronto, Ontario, Canada; ${ }^{2}$ IRCCS Istituto Clinico Humanitas, Rozzano, Italy; ${ }^{3}$ Fondazione IRCCS - Istituto Nazionale dei Tumori, Milano, Italy; ${ }^{4}$ Oregon Health and Science University, Portland, Oregon, US; ${ }^{5}$ Univ. Klinik f. Innere Medizin I, AKH, Wien, Austria; ${ }^{6}$ Masaryk Memorial Cancer Institute, Faculty of Medicine, Masaryk University, Brno, Czech Republic; ${ }^{7}$ Universitaetsklinikum Essen, Zentrum f. Innere Medizin, Essen, Germany; ${ }^{8}$ Institute of Cancer Sciences, University of Manchester, The Christie Hospital, Manchester, UK; ${ }^{9}$ Novartis Pharmaceuticals Corporation, East Hanover, New Jersey, US; ${ }^{10}$ Novartis AG, Basel, Switzerland; ${ }^{11}$ Montefiore Einstein Center for Cancer Care, Bronx, New York, US; ${ }^{12}$ National Cancer Center Hospital, Chuo-ku, Tokyo, Japan; ${ }^{13}$ Seoul National University Hospital, Cancer Research Institute, Seoul National University College of Medicine, Seoul, South Korea; ${ }^{14}$ Dana Farber Cancer Institute, Boston, Massachusetts, US; ${ }^{15}$ Department of Medicine, Moffitt Cancer Center, Tampa, Florida, US; ${ }^{16}$ University of Texas/MD Anderson Cancer Center, Houston, Texas, US; ${ }^{17}$ Charité Universitätsmedizin Berlin, Campus VirchowKlinikum, Berlin, Germany; ${ }^{18}$ European Institute of Oncology, Milan, Italy

\section{Corresponding author:}

Simron Singh, MD,

Sunnybrook Health Sciences Centre,

Toronto, Ontario, Canada

Phone: 416-480-4928

Fax: 617-632-5370

E-mail: simron.singh@sunnybrook.ca

Short Title: Everolimus in NET of GI tract and unknown primary

Funding: This study was funded by Novartis Pharmaceuticals Corporation.

Keywords: Everolimus, neuroendocrine tumors, RADIANT-4, gastrointestinal tract

Word count in text: 3107 words

Number of tables and figures: 2 tables and 3 figures

ABSTRACT: 247 words [max 250 words] 


\section{Abstract \\ Purpose}

The RADIANT-4 randomized phase 3 study demonstrated significant prolongation of median progression-free survival (PFS) with everolimus vs placebo [11.0 months (95\% CI 9.2-13.3) vs 3.9 (3.6-7.4)] in patients with advanced, progressive, nonfunctional GI and lung NET. This analysis specifically evaluated NET patients of GI and unknown primary origin.

\section{Methods}

Patients in the RADIANT-4 trial were randomized 2:1 to everolimus $10 \mathrm{mg} /$ day or placebo. The effect of everolimus on PFS was evaluated in patients with NET of the GI tract or unknown primary site.

\section{Results}

Of the 302 patients enrolled, 175 had GI NET (everolimus, 118; placebo, 57) and 36 had unknown primary (everolimus, 23; placebo, 13). In the GI subset, median PFS (95\% CI) by central review was 13.1 (9.2-17.3) months in the everolimus arm vs 5.4 (3.6-9.3) months in placebo arm; hazard ratio (HR), $0.56(0.37-0.84)$. In the unknown primary patients, the median PFS was 13.6 (4.1-not evaluable) for everolimus vs 7.5 (1.9-18.5) months for placebo; HR, 0.60; (0.24-1.51). Everolimus efficacy was also demonstrated in both midgut and non-midgut populations; a $40-46 \%$ reduction in risk of progression or death was reported for patients in the combined GI and unknown primary subgroup. Everolimus had benefit regardless of prior SSA therapy.

\section{Conclusions}

Everolimus showed a clinically meaningful PFS benefit in patients with advanced progressive nonfunctional NET of GI and unknown primary, consistent with the overall RADIANT-4 results, 
providing an effective new standard treatment option in this patient population and filling an unmet treatment need for these patients. 


\section{Introduction}

Neuroendocrine tumors (NET) are a diverse group of tumors arising from neuroendocrine cells which are located at multiple anatomical sites in the body. Functional NET are associated with clinical symptoms due to hormonal secretion by the tumors; both nonfunctional and functional NET can present with symptoms related to the primary tumor, particularly obstruction, or symptoms from metastatic disease [1-4]. More than $60 \%$ of NET originate in the gastrointestinal (GI) tract, the majority of which are nonfunctional [1, 5-7].

Although the incidence of NET has been seen to be rising $[6,8]$, limited treatment options are currently available for patients with advanced GI NET. Somatostatin analogs (SSA) are the therapy of choice for symptom control [9-11]. Recently, evidence for the efficacy of SSA in tumor control has been demonstrated with antitumor effects (improved progression-free survival [PFS]) of octreotide long-acting repeatable (LAR) first shown in the PROMID study, in patients with well-differentiated metastatic midgut NET [12]. Subsequently, in the phase 3 CLARINET study, lanreotide autogel also showed an improved PFS compared with placebo in patients with advanced, proliferative index (Ki-67) <10\% nonfunctioning, enteropancreatic NET [13]. There are emerging data on efficacy of peptide receptor radiotherapy (PRRT) but access to this is not universal and treatment options beyond SSA still remain limited.

Everolimus, an oral mTOR (mammalian target of rapamycin) inhibitor, [14] has previously demonstrated activity in patients with NET [15-26]. In patients with advanced pancreatic NET, efficacy and safety of everolimus has been demonstrated in the large randomized, double-blind, phase 3 RADIANT-3 study and subsequently has been approved for clinical use [14]. In the phase 3 RADIANT-2 study, a combination of everolimus with octreotide LAR showed a 5.1month increase in median PFS compared with placebo plus octreotide LAR in patients with 
advanced NET associated with carcinoid syndrome; however, this complex study narrowly missed its pre-specified efficacy endpoint [16].

In the recently conducted large phase 3 RADIANT-4 study of 302 patients with advanced, progressive, well- and moderately-differentiated, nonfunctional NET originating in lung, GI tract or unknown primary site, everolimus improved the median PFS by 7.1 months from 3.9 months to 11.0 months and reduced the risk of disease progression or death by 52\% (HR, 0.48; 95\% CI, 0.35-0.67; $P<.00001$ ) [22]. This effect was independent of prior treatment with SSA. However, there is a considerable difference between lung NET and GI NET in terms of presentation, pathophysiology as well as prognosis. Based on the unique biology of each NET disease type it is important to assess each of these unique types of NET independently. This subgroup analysis of the RADIANT-4 study aimed to explore the effect of everolimus in patients with advanced progressive nonfunctional GI or unknown primary NET.

\section{PATIENTS AND METHODS}

\section{Study Design and Endpoints}

RADIANT-4 is a large international, multicenter, randomized, double-blind, placebo-controlled, phase 3 study involving 97 centers in 25 countries which evaluated the efficacy and safety of everolimus in advanced, nonfunctional, radiologically progressive, well- and moderately differentiated GI or lung NET (NCT01524783) [22]. Patients with pancreatic NET or origins other than GI and lung were excluded. Patients with NET of unknown primary site were included according to the following definition: well differentiated (grade [G]1 or G2) NET with primary tumor origin other than GI or lung excluded by appropriate diagnostic procedures. The study was 
stratified for primary tumor types associated with favorable and unfavorable prognosis, prior or no prior SSA exposure and WHO performance status (PS).

Key eligibility criteria included patients aged $\geq 18$ years with pathologically confirmed, advanced (unresectable or metastatic), nonfunctional, well-differentiated [G1 or G2 according to the 2010 WHO classification [13, 14]] NET of GI or lung and documented radiological disease progression within 6 months; a WHO PS score of 0 or 1 . Exclusion criteria included history of carcinoid syndrome, poorly differentiated histology, and pancreatic primary site [22].

The primary endpoint was PFS by central radiology assessment as per modified RECIST version 1.0 [14]. Primary efficacy analyses were assessed on all randomly assigned patients on an intention-to-treat basis. The safety population included all patients who received at least 1 dose of the study drug with at least 1 post baseline safety assessment. Adverse events (AEs) were assessed as per National Cancer Institute Common Terminology Criteria for Adverse Events (CTCAE) version 4.03. The study was approved by respective Institutional Review Boards of participating sites and all patients provided written informed consent to participate.

For the purposes of this analysis, GI origin was defined as primary originating in stomach, colon, rectum, appendix, caecum, ileum, duodenum, jejunum or other origins identified by investigators as GI, mostly from small intestine. Patients with primary tumors of unknown origin were analyzed as a separate group, although it is usually considered that they were likely to be of small intestine origin where NET are often small and difficult to locate, particularly in the setting of metastatic disease (not an uncommon occurrence in NET). In a series of patients with metastatic disease and occult primary tumors examined surgically, primary tumors were found in the small bowel, appendix, colon or rectum in $74.6 \%$ and only $3.2 \%$ were found in the pancreas [27]. 
The GI subgroup was further categorized into midgut and non-midgut origin. Midgut NET included primary tumors originating in the duodenum jejunum, ileum, cecum, appendix, and other origins identified by investigators as GI, mostly from small intestine while non-midgut primary tumors were defined as originating from stomach, colon, and rectum. In addition, the efficacy was assessed in patients from the combined GI and unknown primary origin with respect to prior or no prior exposure to SSA.

Eligible patients were randomly assigned in a 2:1 ratio to receive oral everolimus at a dose of 10 mg per day or placebo, along with best supportive care (BSC). BSC included non-antitumor treatment deemed necessary by the physician, particularly antidiarrheal medication. Treatment was continued until documented radiological disease progression, start of new cancer therapy, development of an intolerable $\mathrm{AE}$, or withdrawal of consent. Crossover from placebo to openlabel everolimus after progression was not allowed until completion of the primary analysis.

\section{Statistical Analysis}

The median PFS was estimated using the Kaplan-Meier method.[26] The relative risk of disease progression or death comparing everolimus and placebo arms was estimated by an unstratified Cox proportional hazards model unless otherwise stated and presented as hazard ratio (HR). For the analyses of PFS by tumor origin, all HRs were unstratified and unadjusted for any covariates. In the primary analysis based on the overall population, patients were stratified based on prior SSA exposure as per randomization data. However for prior SSA subgroup analysis presented here, patients were classified in the prior SSA subgroups (Yes vs. No) based on data from the case report forms and not on randomization data. 


\section{RESULTS}

\section{Baseline Patients and Disease Characteristics}

Of the 302 patients in the RADIANT 4 trial, 175 patients had GI NET (everolimus, $\mathrm{n}=118$ and placebo, $\mathrm{n}=57$ ) and 36 patients had unknown primary (everolimus, $\mathrm{n}=23$ and placebo, $\mathrm{n}=13$ ) (CONSORT Patient Flow Chart; Supplementary Figure). Detailed baseline characteristics are listed in Table 1.

\section{Efficacy}

\section{GI and Unknown Primary Subgroup: PFS by Central Review}

In the GI subgroup, a median PFS of 13.1 months (95\% CI, 9.2-17.3) was observed in the everolimus arm compared with 5.4 months (95\% CI, 3.6-9.3) in the placebo arm (Figure 1). In patients with unknown primary, median PFS for everolimus was 13.6 months (95\% CI, 4.1 - not evaluable) vs 7.5 months (95\% CI, 1.9-18.5) for placebo (Figure 1). The subgroup analyses demonstrated a consistent positive treatment effect with everolimus in all but the subgroup of patients with ileal tumors (Figure 2). It is likely that a beneficial effect may still be present in this more indolent population, although it is probably of a lower magnitude which, in conjunction with other confounding factors resulted in the observed differences in HRs between the ileal subgroup and other subgroups. To minimize the effects of small subgroups presented in Figure 2, we retrospectively analyzed broader midgut vs non-midgut subgroups, which also has clinical validity since NET are often classified as such in clinical practice.

\section{Midgut vs Non-midgut Subgroup: PFS by Central Review}


In the analysis of midgut $(n=115)$ vs non-midgut $(n=60)$ origin, in patients with midgut NET, everolimus showed a 6.4-month prolongation in median PFS over placebo and a $29 \%$ reduction in the risk of progression or death based on unstratified Cox regression analysis (Figure 3A). In patients with non-midgut NET, everolimus showed a 6.2 -month increase in the median PFS over placebo and a 73\% reduction in the risk of progression or death (Figure 3B).

\section{Prior-SSA vs No prior-SSA Subgroup: PFS by Central Review}

Everolimus showed efficacy regardless of prior treatment with SSA as evaluated in the combined GI and unknown primary subgroups. Everolimus demonstrated an increase in median PFS of 6.7 months in patients with prior SSA exposure compared to placebo, with a $46 \%$ reduction in the risk of progression or death based on unstratified Cox regression analysis (Figure 3C), while in patients with no prior SSA, everolimus showed an increase in median PFS of 9.1 months compared to placebo with a $40 \%$ reduction in risk of progression or death based on unstratified Cox regression analysis (Figure 3D).

\section{Safety}

The safety set in the GI subgroup included data from 117 patients in the everolimus and 58 patients in the placebo arm. In the unknown primary subgroup, safety set included data from 22 patients in the everolimus and 13 patients in the placebo arm. Dose reductions or temporary treatment interruptions (not adjusted for treatment duration) occurred in 79 (68\%) and 13 (59\%) patients receiving everolimus vs 16 (28\%) and 5 (39\%) patients receiving placebo in the GI and the unknown primary subgroups, respectively. Rates of on-treatment deaths (occurring during study medication or within 30 days of treatment discontinuation) were $3 \%$ (4 patients) and 5\% (1 patient) in the everolimus group vs $2 \%$ (1 patient) and $0 \%$ in the placebo group for the GI and 
the unknown primary subgroups, respectively. Of these on-treatment deaths, in the GI subgroup, 2 deaths (2\%, one case each due to respiratory failure and septic shock) in the everolimus group and 1 death (2\%, due to lung infection) in the placebo group were attributed to causes other than disease progression. In the unknown primary subgroup, the one observed death was due to disease progression.

Adverse events were consistent with the known safety profile of everolimus and were mostly grade 1 or 2 . Drug-related adverse events occurring in at least $10 \%$ of patients for patients with GI and unknown primary are listed in Table 2. The most common were stomatitis, diarrhea, infections and fatigue in both the GI and the unknown primary subgroups. Drug-related grade 3 or 4 adverse events included stomatitis, diarrhea, anemia, and fatigue in both the GI and the unknown primary subgroups. Treatment discontinuation due to grade 3 or 4 adverse events related to the study drug were reported in 15 (13\%) patients receiving everolimus and in 1 (2\%) patient receiving placebo for the GI subgroup while in the unknown primary subgroup, no grade 3 or 4 events led to treatment discontinuation. In the GI subgroup, everolimus-associated noninfectious pneumonitis was seen in 22 patients (19\%); most were of grade 1 or 2 severity; grade 3 pneumonitis was see in one patient (1\%) and no grade 4 cases were reported. One grade 2 (5\%) and one grade 3 (5\%) non-infectious pneumonitis were reported in the unknown primary subgroup. No new safety signals, including GI toxicities, were determined as compared to the overall RADIANT-4 study population. 
Page 11 of 23 


\section{Discussion}

Neuroendocrine neoplasms are a rare, heterogeneous population of cancers. Consequently, it has been historically difficult to perform robust, high-quality randomized clinical trials. One effective strategy has been to conduct large phase 3 trials with different subgroups of NET primaries. The RADIANT-4 study is a groundbreaking trial for non-functioning NET of GI and lung which demonstrates significant clinical benefit of everolimus, further supporting the previously observed benefit of everolimus in pancreatic NET [14]. However, given the heterogeneity of this patient population, subgroup analysis is of utmost importance to understand the effect of everolimus treatment on individual NET populations. Considering intestinal NET make up the majority of NET, examining this population specifically is of high clinical relevance and necessary to aid clinicians to best determine the benefit of everolimus treatment in individual patients. This GI subgroup analysis of the RADIANT-4 population is timely as recent results of the NETTER-1 trial show a benefit of PRRT in the midgut population. Without specific knowledge of the effect of everolimus therapy on the GI population (specifically midgut NET), it will be difficult for clinicians to determine appropriate treatment for their patients.

This analysis confirmed a clinically meaningful PFS benefit in the subgroup of NET patients with GI and unknown primary treated in the everolimus arm of the RADIANT-4 study, of a similar degree to the overall RADIANT-4 cohort. In both the midgut and non-midgut subgroups, everolimus showed a marked improvement in median PFS and a reduction in the risk of progression or death compared with placebo. The $\geq 40 \%$ reduction in risk of progression or death seen in patients with or without prior SSA therapy is clinically meaningful (as many patients may start with SSA) and of a similar degree to that of the previously reported overall cohort. Everolimus is an effective treatment option as a treatment for SSA naïve patients as well as those 
pre-treated with SSA. In many NET patients, everolimus now represents a promising treatment option fulfilling a previously unmet need.

When considering the benefit of everolimus according to primary site, there appears to be a slightly lesser degree of observable effect for patients with tumor originating in the ileum at first observation. This may partly be due to the more indolent nature of ileal NETs compared with NETs of other sites: the median PFS on the placebo arm was 16.7 months in the ileal NET subgroup compared to 3.9 months in the overall RADIANT-4 population. However, the HR values for the individual GI subgroups should be interpreted with caution due to possible influence of imbalances in the stratification factors as well as in other prognostic factors. In addition, variability related to small sample size, especially due to the small number of PFS events within the majority of the subgroups, could explain part of the numerical differences between the HRs across different tumor locations. In further analysis of the ileum subgroup, pharmacokinetic analysis showed adequate therapeutic doses available in the ileum subgroup, ruling out drug exposure as a potential cause. Better prognosis of the ileum subgroup is reflected in the rather long median PFS in the placebo arm; 16.7 months for the ileum subgroup compared with 3.9 months for the overall RADIANT-4 study population (data not shown). However, the number of events was too low in this subset of patients to draw any conclusions on the comparative efficacy of everolimus across prognostic levels. Consequently, the limited follow up times of the study (median of 21 months) may not have allowed maturation of the data in the ileum subgroup to fully evaluate the effect of everolimus on the ileum population. The possibility however, of a lower effect of everolimus on the ileum subgroup cannot be excluded and must be further investigated, although it seems highly unlikely given the biological background and lack of data indicating that ileum NET could have lower mTOR activation than 
other NET [28-30]. The activation of the mTOR pathway appears to be a consistent effect in all NET $[14,15]$.

It is important to highlight that the RADIANT-4 study enrolled a population of patients with progressive NET as reflected by the 3.9 months median PFS in the placebo arm for the overall population [22]. Earlier studies in patients with NET such as the RADIANT-2 and the CLARINET study enrolled patients with less aggressive disease compared with the RADIANT-4 study population. In the RADIANT-2 study of patients with advanced NET with carcinoid syndrome, the placebo arm showed a median PFS of 11.3 months [15]. While the CLARINET study enrolled GEP-NET patients with RECIST-based stable disease (placebo arm, 18.0 months PFS) with the primary tumor site in the GI being primarily midgut [12]. Comparable to the overall RADIANT-4 population, the GI and unknown primary subgroups also showed a shorter median PFS (5.4 months and 7.4 months, respectively) in the placebo groups indicative of the more aggressive tumor biology in these subgroups. The marked improvement in PFS upon everolimus treatment in these aggressive patient populations demonstrates the efficacy of everolimus in patients with progressive NET where treatment options remain very limited. In particular, for the non-midgut population, everolimus showed a marked 6.2-month increase in median PFS compared with the patients who received placebo, who had a very short median PFS of only 1.9 months. In these more aggressive NET populations, everolimus appears to be a very effective new standard option.

The safety profile of everolimus in the RADIANT-4 study was consistent with previouslyreported studies in advanced NET and no new safety signals were observed in the GI subgroup settings $[15,22]$. The most common AEs related to everolimus treatment were stomatitis, infections, diarrhea, peripheral edema, and fatigue in both the GI and the unknown primary 
subgroups and were mainly grade 1 and 2. Treatment-related grade 3 or 4 AEs leading to treatment discontinuation were seen only in $13 \%$ of the patients in the GI subgroup while no treatment discontinuation due to everolimus treatment-related grade 3 or 4 AEs were seen in the unknown primary subgroup. Thus, no noticeable difference in safety and adverse effects in the GI and unknown primary subgroups were observed as compared to the overall RADIANT-4 population.

As in most subgroup analyses, this analysis carries limitations as the results may have been confounded by prognostic variances in the 2 arms of the subgroups. However, results of the subgroups analyzed in this study showed consistent improvements in PFS with everolimus as was observed for the overall RADIANT-4 study.

\section{Conclusion}

In summary, in this analysis of the RADIANT-4 study, everolimus showed clinicallymeaningful improvements in the median PFS in nonfunctional progressive NET of GI and unknown primary compared with placebo. The safety findings were similar to previously reported studies. Everolimus thus presents an effective new standard treatment option in patients with advanced progressive nonfunctional GI NET and NET of unknown primary. 


\section{Acknowledgements:}

The authors acknowledge the patients, their families, and their caregivers, as well as the investigators and research nurses. The RADIANT-4 study group is grateful to all the physicians who contributed to the present study; the worldwide network of research nurses, trial coordinators, and operations staff for their contributions. We appreciate the support of the colleagues of the RADIANT-4 Study Team who contributed to the presented data. In addition, we thank Anamika Gulati from Novartis Healthcare Pvt. Ltd. for providing medical editorial assistance. We would like to thank Caroline Sachs for her contributions to the study.

Ethics approval: Written informed consent was obtained from all study participants, and the study protocol was approved by the institutional research ethics review board at each study centre.

\section{AUTHOR CONTRIBUTIONS}

SS, JCY, MEP, JS, NF, and MK planned and designed the study. LBP and MV provided the administrative support to the study. JL, MV, LBP contributed in collection and assembly of the data. MV, LBP, JL, JCY, MEP, JS, NF, MK, with inputs from all authors contributed towards data analysis and data interpretation. All authors critically reviewed the manuscript for important intellectual content and approved the final version of the manuscript 


\section{Competing Interests:}

SS has received honoraria, consulting or advisory fees, travel and accomodation expenses, and research funding from Novartis. RB has received research funding from Italfarmaco, Novartis, and and Otsuka and travel and accommodations expenses from Ipsen; Italfarmaco; and Novartis. RFP has received consulting fees and is on speaker's bureau for Novartis. MR has received honoraria from Celgene, Ipsen, Novartis, and Roche and consulting or advisory fees from Celgene, Ipsen, Novartis, and Roche. JT has received honoraria, research funding, and travel and accommodations expenses from Novartis. HL has received honoraria from Ipsen, Novartis, and Pfizer, consulting or advisory fees from Novartis and Pfizer, research funding from Novartis and travel and accommodations expenses from Ipsen, Novartis, and Pfizer. JWV has received honoraria, consulting or advisory fees and research funding from Novartis. MV and LBP are employees of and own shares in Novartis. CC, JL, and DOH declare no conflicts of interests. EW has received consulting or advisory fees from Celgene, Ipsen, and Novartis. NO has received research funding from Novartis, Teijin, Otsuka, and Taiho. SKL has received travel and accommodations expenses and research funding from Oxigene. MHK has received consulting or advisory fees from Ipsen and Novartis. JS has received honoraria from Novartis, consulting or advisory fees from Ipsen, Lexicon, and Novartis, research funding from Novartis and Pfizer, and is on the speaker's bureau for Bayer and Genentech. JCY has received consulting or advisory fees from Ipsen, Lexicon, and Novartis and research funding from Novartis. MEP has received honoraria from Ipsen, Lexicon, Novartis, and Pfizer, consulting or advisory fees from Ipsen, Lexicon, Novartis, and Pfizer, research funding from Novartis, and travel and accommodations expenses from Ipsen and Novartis. NF has received honoraria from Ipsen, and Novartis, 
consulting or advisory fees from Ipsen, Lexicon, Novartis, and Italfarmaco, research funding from Novartis, and travel and accommodations expenses from Ipsen and Novartis. 


\section{References:}

1 Vinik AI, Woltering EA, Warner RR, et al: Nanets consensus guidelines for the diagnosis of neuroendocrine tumor. Pancreas 2010;39:713-734.

2 Eads JR and Meropol NJ: A new era for the systemic therapy of neuroendocrine tumors. The Oncologist 2012;17:326-338.

3 Oberg K: Neuroendocrine gastro-enteropancreatic tumors - from eminence based to evidence-based medicine - a scandinavian view. Scand J Gastroenterol 2015;50:727-739.

4 Detterbeck FC: Clinical presentation and evaluation of neuroendocrine tumors of the lung. Thorac Surg Clin 2014;24:267-276.

5 Modlin IM, Lye KD, Kidd M: A 5-decade analysis of 13,715 carcinoid tumors. Cancer 2003;97:934-959.

6 Yao JC, Hassan M, Phan A, et al: One hundred years after "carcinoid": Epidemiology of and prognostic factors for neuroendocrine tumors in 35,825 cases in the united states. J Clin Oncol 2008;26:3063-3072.

7 Taal BG and Visser O: Epidemiology of neuroendocrine tumours. Neuroendocrinology 2004;80 Suppl 1:3-7.

8 Hallet J, Singh S, Law CH: Neglected conditions: Neuroendocrine tumours. Can Med Assoc J 2014;186:452.

9 Bajetta E, Procopio G, Catena L, et al: Lanreotide autogel every 6 weeks compared with lanreotide microparticles every 3 weeks in patients with well differentiated neuroendocrine tumors: A phase iii study. Cancer 2006;107:2474-2481.

10 Reubi JC, Maurer R, von Werder K, et al: Somatostatin receptors in human endocrine tumors. Cancer Res 1987;47:551-558. 
11 Janson ET, Westlin JE, Eriksson B, et al: [111in-dtpa-d-phe1]octreotide scintigraphy in patients with carcinoid tumours: The predictive value for somatostatin analogue treatment. Eur $\mathrm{J}$ Endocrinol 1994;131:577-581.

12 Rinke A, Muller HH, Schade-Brittinger C, et al: Placebo-controlled, double-blind, prospective, randomized study on the effect of octreotide lar in the control of tumor growth in patients with metastatic neuroendocrine midgut tumors: A report from the promid study group. $\mathrm{J}$ Clin Oncol 2009;27:4656-4663.

13 Caplin ME, Pavel M, Cwikla JB, et al: Lanreotide in metastatic enteropancreatic neuroendocrine tumors. N Engl J Med 2014;371:224-233.

14 Yao JC, Phan AT, Chang DZ, et al: Efficacy of rad001 (everolimus) and octreotide lar in advanced low- to intermediate-grade neuroendocrine tumors: Results of a phase ii study. J Clin Oncol 2008;26:4311-4318.

15 Yao JC, Shah MH, Ito T, et al: Everolimus for advanced pancreatic neuroendocrine tumors. N Engl J Med 2011;364:514-523.

16 Pavel ME, Hainsworth JD, Baudin E, et al: Everolimus plus octreotide long-acting repeatable for the treatment of advanced neuroendocrine tumours associated with carcinoid syndrome (radiant-2): A randomised, placebo-controlled, phase 3 study. Lancet 2011;378:20052012.

17 Ito T, Okusaka T, Ikeda M, et al: Everolimus for advanced pancreatic neuroendocrine tumours: A subgroup analysis evaluating japanese patients in the radiant-3 trial. Jpn J Clin Oncol 2012;42:903-911. 
18 Fazio N, Granberg D, Grossman A, et al: Everolimus plus octreotide long-acting repeatable in patients with advanced lung neuroendocrine tumors: Analysis of the phase 3, randomized, placebo-controlled radiant-2 study. Chest 2013;143:955-962.

19 Lombard-Bohas C, Yao JC, Hobday T, et al: Impact of prior chemotherapy use on the efficacy of everolimus in patients with advanced pancreatic neuroendocrine tumors: A subgroup analysis of the phase iii radiant-3 trial. Pancreas 2015;44:181-189.

20 Anthony LB, Pavel ME, Hainsworth JD, et al: Impact of previous somatostatin analogue use on the activity of everolimus in patients with advanced neuroendocrine tumors: Analysis from the phase iii radiant-2 trial. Neuroendocrinology 2015;102:18-25.

21 Yao J, Wang JY, Liu Y, et al: A randomized phase ii study of everolimus for advanced pancreatic neuroendocrine tumors in chinese patients. Med Oncol 2014;31:251.

22 Yao JC, Fazio N, Singh S, et al: Everolimus for the treatment of advanced, nonfunctional neuroendocrine tumours of the lung or gastrointestinal tract (radiant-4): A randomised, placebo-controlled, phase 3 study. Lancet 2015;387:968-977.

23 Panzuto F, Rinzivillo M, Fazio N, et al: Real-world study of everolimus in advanced progressive neuroendocrine tumors. The Oncologist 2014;19:966-974.

24 Chan JA, Blaszkowsky L, Stuart K, et al: A prospective, phase 1/2 study of everolimus and temozolomide in patients with advanced pancreatic neuroendocrine tumor. Cancer 2013;119:3212-3218.

25 Chan JA, Ryan DP, Zhu AX, et al: Phase i study of pasireotide (som 230) and everolimus (rad001) in advanced neuroendocrine tumors. Endocr Relat Cancer 2012;19:615-623. 
26 Oh DY, Kim TW, Park YS, et al: Phase 2 study of everolimus monotherapy in patients with nonfunctioning neuroendocrine tumors or pheochromocytomas/paragangliomas. Cancer 2012;118:6162-6170.

27 Massimino KP, Han E, Pommier SJ, et al: Laparoscopic surgical exploration is an effective strategy for locating occult primary neuroendocrine tumors. Am J Surg 2012;203:628631.

28 Geis C, Fendrich V, Rexin P, et al: Ileal neuroendocrine tumors show elevated activation of mammalian target of rapamycin complex. J Surg Res 2015;194:388-393.

29 Kasajima A, Pavel M, Darb-Esfahani S, et al: Mtor expression and activity patterns in gastroenteropancreatic neuroendocrine tumours. Endocr Relat Cancer 2011;18:181-192.

30 Qian ZR, Ter-Minassian M, Chan JA, et al: Prognostic significance of mtor pathway component expression in neuroendocrine tumors. J Clin Oncol 2013;31:3418-3425. 


\section{Legends to figures}

\section{Figure 1. PFS in patients with GI and Unknown primary subgroups}

Kaplan-Meier estimates of progression-free survival in GI subgroup (A) and Unknown primary subgroup (B). Progression-free survival was assessed by central radiology review. The HRs are obtained from unstratified Cox model.

BSC, best supportive care; CI, confidence interval; HR, hazard ratio.

\section{Figure 2. PFS treatment effect for patient primary tumor site per central review}

Forest plots show the effect of study treatment on PFS events in GI subgroup with multiple primary tumor location. The HRs in subgroups are obtained from stratified Cox model. All hazard ratios presented for these subgroup analyses were stratified by prior SSA, WHO performance status and tumor origin

CI, confidence interval; CUP, unknown primary; HR, hazard ratio; NE, not-evaluable; PFS, progression-free survival.

\section{Figure 3. PFS in patients with midgut*, non-midgut** and prior-SSA, no prior-SSA} subgroups

Kaplan-Meier estimates of progression-free survival in midgut (A), non-midgut (B) priorsomatostatin analogs (C) and no prior- somatostatin analogs (D) subgroups were assessed by central radiology review. *Duodenum $(\mathrm{n}=10)$ is included under midgut subgroup assuming they were located distally. **Patient with intra-ampullary tumor $(n=1)$ is included under non-midgut subgroup. The HRs are obtained from unstratified Cox model.

BSC, best supportive care; CI, confidence interval; HR, hazard ratio; SSA, somatostatin analogs. 
Table 1. Baseline patients and Disease Characteristics

\begin{tabular}{|c|c|c|c|c|}
\hline \multirow[t]{2}{*}{ Characteristic } & \multicolumn{2}{|c|}{$\begin{array}{c}\text { Gastrointestinal } \\
(\mathrm{N}=175)\end{array}$} & \multicolumn{2}{|c|}{$\begin{array}{c}\text { Unknown Primary } \\
(\mathrm{N}=36)\end{array}$} \\
\hline & $\begin{array}{c}\text { Everolimus } \\
\mathrm{N}=118\end{array}$ & $\begin{array}{l}\text { Placebo } \\
\mathrm{N}=57\end{array}$ & $\begin{array}{l}\text { Everolimus } \\
\quad \mathrm{N}=23\end{array}$ & $\begin{array}{c}\text { Placebo } \\
\mathrm{N}=13\end{array}$ \\
\hline Age, median (range) & $63.0(22-83)$ & $60.0(33-83)$ & $60.0(23-80)$ & $60.0(34-81)$ \\
\hline Male & $40.7 \%$ & $54.4 \%$ & $34.8 \%$ & $53.8 \%$ \\
\hline \multicolumn{5}{|l|}{ WHO performance status } \\
\hline $\mathbf{0}$ & $75.4 \%$ & $84.2 \%$ & $60.9 \%$ & $53.8 \%$ \\
\hline 1 & $24.6 \%$ & $15.8 \%$ & $39.1 \%$ & $46.2 \%$ \\
\hline \multicolumn{5}{|l|}{ Race } \\
\hline Caucasian & $77.1 \%$ & $63.2 \%$ & $78.3 \%$ & $61.5 \%$ \\
\hline Asian & $16.9 \%$ & $21.1 \%$ & $17.4 \%$ & $30.8 \%$ \\
\hline Others $^{*}$ & $5.9 \%$ & $15.8 \%$ & $4.3 \%$ & $7.7 \%$ \\
\hline \multicolumn{5}{|l|}{ Ki-67 index by primary tumor ${ }^{\mathrm{s}}$} \\
\hline $\begin{array}{l}\leq 2 \% \text { Ki-67 index or }<2 \\
\text { mitoses/10HPF }\end{array}$ & $45.8 \%$ & $35.1 \%$ & $26.1 \%$ & $15.4 \%$ \\
\hline $\begin{array}{l}\text { 3-20\% Ki-67 index or } 2-20 \\
\text { mitoses/10HPF }\end{array}$ & $43.2 \%$ & $52.6 \%$ & $65.2 \%$ & $61.5 \%$ \\
\hline $\begin{array}{l}>20 \% \text { Ki-67 index or }>20 \\
\text { mitoses/10HPF }\end{array}$ & $0 \%$ & $0 \%$ & $0 \%$ & $7.7 \%$ \\
\hline Not done & $10.2 \%$ & $12.3 \%$ & $8.7 \%$ & $15.4 \%$ \\
\hline \multicolumn{5}{|l|}{ Liver tumor burden } \\
\hline $\mathbf{0 \%}$ & $14.4 \%$ & $10.5 \%$ & $8.7 \%$ & $23.1 \%$ \\
\hline$>0-10 \%$ & $66.1 \%$ & $66.7 \%$ & $34.8 \%$ & $46.2 \%$ \\
\hline$>10-25 \%$ & $11.0 \%$ & $8.8 \%$ & $26.1 \%$ & $7.7 \%$ \\
\hline$>25-50 \%$ & $2.5 \%$ & $3.5 \%$ & $13.0 \%$ & $7.7 \%$ \\
\hline$>50 \%$ & $4.2 \%$ & $10.5 \%$ & $17.4 \%$ & $15.4 \%$ \\
\hline Unknown & $1.7 \%$ & $0 \%$ & $0 \%$ & $0 \%$ \\
\hline \multicolumn{5}{|l|}{ Primary tumor origin } \\
\hline Ileum & $39.8 \%$ & $42.1 \%$ & NA & NA \\
\hline Rectum & $21.2 \%$ & $26.3 \%$ & NA & NA \\
\hline Jejunum & $13.6 \%$ & $10.5 \%$ & NA & NA \\
\hline Stomach & $5.9 \%$ & $7.0 \%$ & NA & NA \\
\hline Duodenum & $6.8 \%$ & $3.5 \%$ & NA & NA \\
\hline Colon & $4.2 \%$ & $5.3 \%$ & NA & NA \\
\hline Cecum & $3.4 \%$ & $1.8 \%$ & NA & NA \\
\hline Appendix & $0.8 \%$ & $0 \%$ & NA & NA \\
\hline Others & $4.2 \%$ & $3.5 \%$ & NA & NA \\
\hline Unknown & $0 \%$ & $0 \%$ & $100 \%$ & $100 \%$ \\
\hline \multicolumn{5}{|l|}{ Tumor grade $^{\ddagger}$} \\
\hline Grade 1 & $73.7 \%$ & $77.2 \%$ & $65.2 \%$ & $61.5 \%$ \\
\hline Grade 2 & $26.3 \%$ & $22.8 \%$ & $34.8 \%$ & $38.5 \%$ \\
\hline \multicolumn{5}{|c|}{ Histologic differentiation or morphology } \\
\hline Well differentiated & $50.8 \%$ & $61.4 \%$ & $56.5 \%$ & $53.8 \%$ \\
\hline Moderately differentiated & $5.1 \%$ & $3.5 \%$ & $4.3 \%$ & $0 \%$ \\
\hline Not done & $44.1 \%$ & $35.1 \%$ & $39.1 \%$ & $46.2 \%$ \\
\hline
\end{tabular}




\begin{tabular}{|l|c|c|c|c|}
\hline Liver & $86.4 \%$ & $91.2 \%$ & $87.0 \%$ & $69.2 \%$ \\
\hline $\begin{array}{l}\text { Para-aortic abdominal lymph } \\
\text { node }\end{array}$ & $19.5 \%$ & $8.8 \%$ & $26.1 \%$ & $30.8 \%$ \\
\hline Peritoneum & $18.6 \%$ & $15.8 \%$ & $13.0 \%$ & $0 \%$ \\
\hline Lung & $16.9 \%$ & $15.8 \%$ & $17.4 \%$ & $23.1 \%$ \\
\hline Prior treatments & \multicolumn{5}{|l|}{} \\
\hline Somatostatin analogs & $58.5 \%$ & $63.2 \%$ & $52.2 \%$ & $53.8 \%$ \\
\hline Chemotherapy & $18.6 \%$ & $12.3 \%$ & $30.4 \%$ & $23.1 \%$ \\
\hline Radiotherapy ${ }^{\#}$ & $13.6 \%$ & $7.0 \%$ & $8.7 \%$ & $15.4 \%$ \\
\hline Surgery & $69.5 \%$ & $84.2 \%$ & $26.1 \%$ & $30.8 \%$ \\
\hline
\end{tabular}

*Included Black and Others. "For tumor grade, "low Ki-67” was defined as Ki-67 index $\leq 2 \%$ (G1); "high Ki-67” was defined as Ki-67 index >2\% (G2); "low mitotic index" was defined as <2 mitoses/10HPF (G1); "high mitotic index" as $\geq 2$ mitoses/10HPF (G2). Based on a mapping between histological grade and WHO grade. "Includes PRRT 
Table 2. Adverse events suspected to be study drug related in patients with GI subgroup and unknown primary subgroup $(\geq 10 \%$ in the everolimus arm)

\begin{tabular}{|c|c|c|c|c|}
\hline \multicolumn{5}{|c|}{ Gastrointestinal Subgroup $^{\#}$} \\
\hline & \multicolumn{2}{|c|}{$\begin{array}{c}\text { Everolimus } \\
\mathbf{N}=117\end{array}$} & \multicolumn{2}{|c|}{$\begin{array}{c}\text { Placebo } \\
\mathbf{N}=58\end{array}$} \\
\hline Adverse events (\%) & All grades & Grade 3/4 & All grades & Grade 3/4 \\
\hline Stomatitis $^{*}$ & 65.0 & 7.7 & 17.2 & 0 \\
\hline Infections $^{\dagger}$ & 33.3 & 7.7 & 3.4 & 0 \\
\hline Diarrhea & 34.2 & 9.4 & 20.7 & 3.4 \\
\hline Fatigue & 31.6 & 3.4 & 27.6 & 1.7 \\
\hline Peripheral edema & 27.4 & 1.7 & 5.2 & 1.7 \\
\hline Rash & 24.8 & 0.9 & 8.6 & 0 \\
\hline Nausea & 17.9 & 0.9 & 8.6 & 0 \\
\hline Dysgeusia & 17.9 & 0.9 & 5.2 & 0 \\
\hline Anemia & 16.2 & 5.1 & 0 & 0 \\
\hline Pneumonitis & 14.5 & 0.9 & 0 & 0 \\
\hline Pruritus & 14.5 & 0 & 3.4 & 0 \\
\hline Decreased appetite & 13.7 & 0.9 & 6.9 & 0 \\
\hline Asthenia & 13.7 & 1.7 & 6.9 & 0 \\
\hline Dermatitis acneiform & 12.8 & 0 & 5.2 & 0 \\
\hline Cough & 12.8 & 0 & 3.4 & 0 \\
\hline Headache & 10.3 & 0 & 6.9 & 0 \\
\hline Epistaxis & 10.3 & 0 & 0 & 0 \\
\hline \multicolumn{5}{|c|}{ Unknown Primary Subgroup } \\
\hline & \multicolumn{2}{|c|}{$\begin{array}{c}\text { Everolimus } \\
\mathbf{N}=22\end{array}$} & \multicolumn{2}{|c|}{$\begin{array}{c}\text { Placebo } \\
\mathbf{N}=13\end{array}$} \\
\hline Stomatitis $^{*}$ & 63.6 & 13.6 & 15.4 & 0 \\
\hline Infections $^{\dagger}$ & 27.3 & 0 & 7.7 & 0 \\
\hline Diarrhea & 31.8 & 4.5 & 15.4 & 0 \\
\hline Fatigue & 22.7 & 4.5 & 15.4 & 0 \\
\hline Weight decreased & 13.6 & 4.5 & 0 & 0 \\
\hline Cough & 13.6 & 0 & 0 & 0 \\
\hline Asthenia & 13.6 & 0 & 7.7 & 0 \\
\hline Decreased appetite & 13.6 & 0 & 0 & 0 \\
\hline Dyspnea & 13.6 & 0 & 0 & 0 \\
\hline Rash & 13.6 & 0 & 15.4 & 0 \\
\hline
\end{tabular}

" Includes stomatitis, aphthous stomatitis, mouth ulceration, and tongue ulceration. ${ }^{\dagger}$ Includes all infections. ${ }^{\ddagger}$ Includes pneumonitis, interstitial lung disease. "In GI subgroup, 1 patient randomized to everolimus arm inadvertently received only placebo treatment because of dispensation error at site, therefore, included in the placebo arm. 



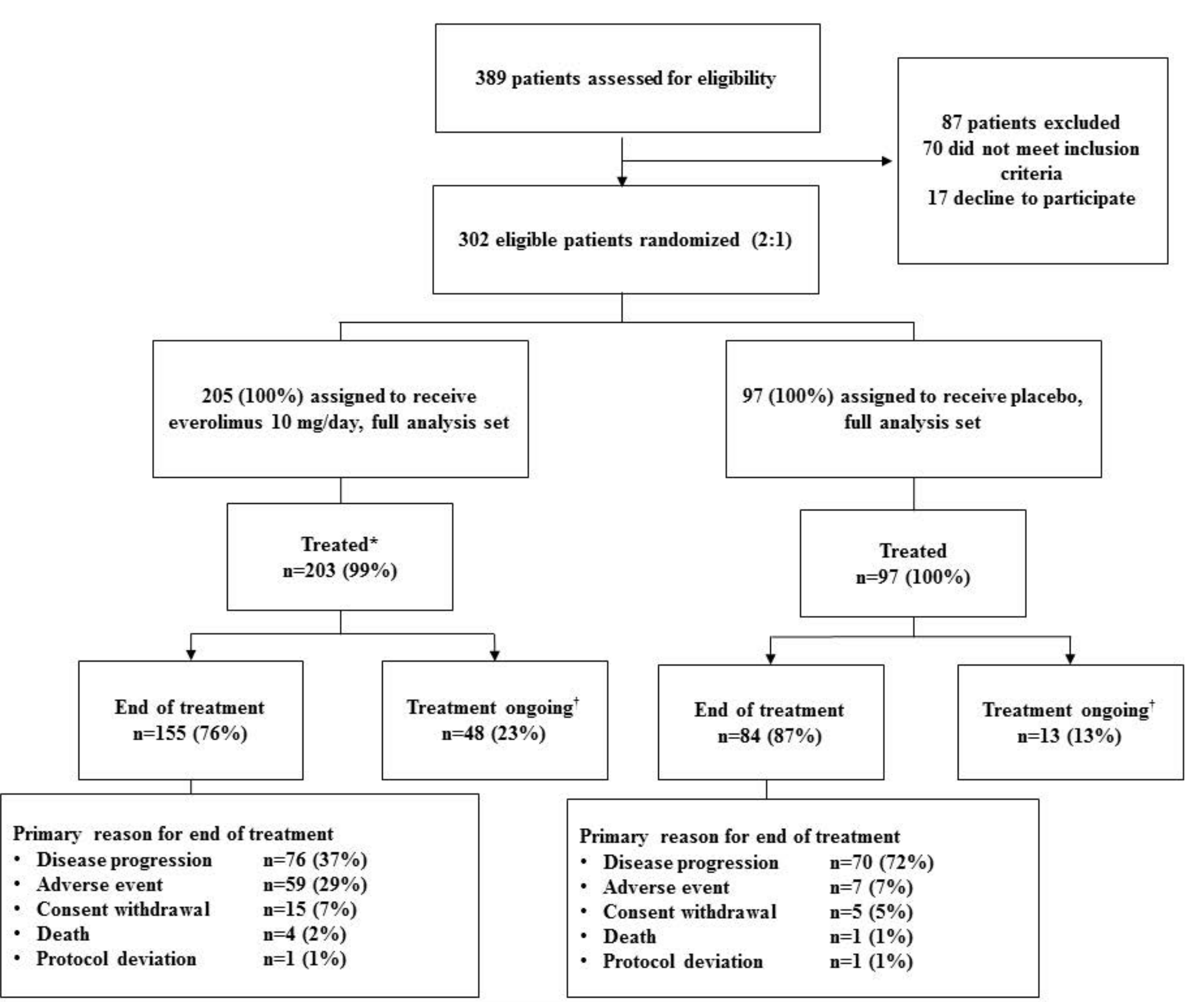

Post-hoc analysis

\begin{tabular}{|c|c|c|c|c|}
\hline \multicolumn{2}{|c|}{$\begin{array}{c}\text { Gastrointestinal } \\
(\mathrm{N}=118)\end{array}$} & \multirow[t]{2}{*}{$\begin{array}{l}\text { Unknown primary } \\
\qquad(\mathrm{N}=\mathbf{2 3})\end{array}$} & \multicolumn{2}{|c|}{$\begin{array}{c}\text { Gastrointestinal } \\
\qquad(N=57)\end{array}$} \\
\hline $\begin{array}{l}\text { Midgut } \\
(\mathrm{N}=80)\end{array}$ & $\begin{array}{c}\text { Non- } \\
\text { Midgut } \\
(\mathrm{N}=38)\end{array}$ & & $\begin{array}{l}\text { Midgut } \\
(\mathrm{N}=35)\end{array}$ & $\begin{array}{l}\text { Non- } \\
\text { Midgut } \\
(\mathrm{N}=22)\end{array}$ \\
\hline
\end{tabular}

Unknown primary

(N=13)

*The full analysis set comprised all 302 randomly assigned patients (205 patients in the everolimus group and 97 in the placebo group). Two patients randomly assigned to everolimus were not treated due to withdrawal of consent and protocol deviation and one patient randomly assigned to everolimus inadvertently received placebo treatment because of dispensation error at site; therefore, the safety set contains 202 patients in the everolimus group and 98 in the placebo group. †At data cutoff (Nov 28, 2014). 


\section{PFS events}

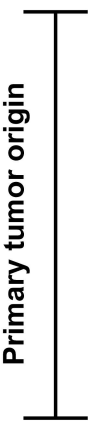

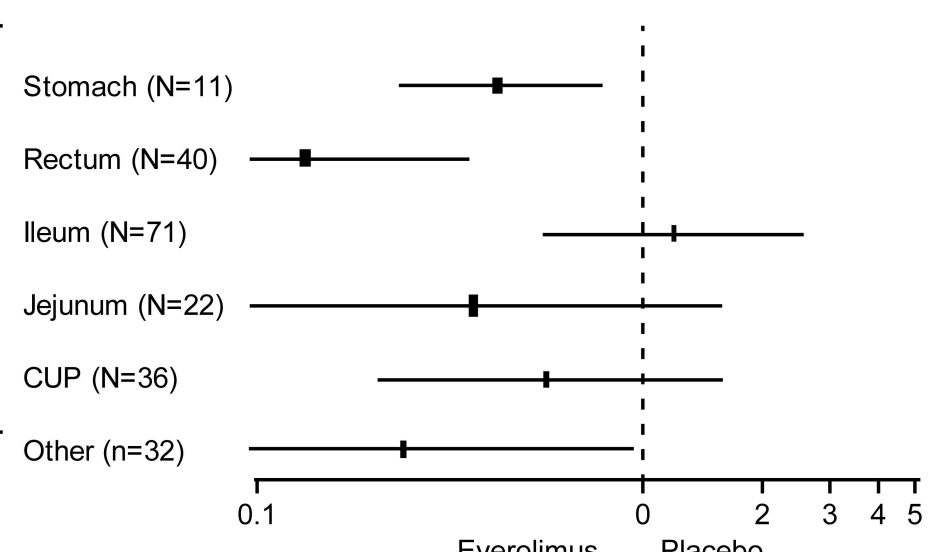

Everolimus Placebo
Hazard Ratio

$[95 \% \mathrm{Cl}]$

NE

$0.14[0.05-0.37]$

1.22 [0.56-2.65]

0.37 [0.08-1.64]

0.58 [0.21-1.58]

0.25 [0.07-0.95]
Everolimus

$3 / 7(42.9)$

$21 / 25$ (84.0)

22/47 (46.8)

$5 / 16$ (31.3)

$11 / 23(47.8)$

9/24 (37.5) $\mathrm{n} / \mathrm{N}(\%)$
PFS, median (95\% Cl)

Everolimus

$\mathrm{N}=205$

Placebo

n/N (\%)

$4 / 4(100)$

9.4 (1.2, NE)

$2.0(1.7,3.5)$

14/15 (93.3)

$7.4(5.5,11.1) \quad 1.9(1.7,3.6)$

$11 / 24(45.8)$

$16.6(9.2,17.7) 16.7(7.4,29.4)$

5/6 (83.3)

$17.3(3.5, \mathrm{NE}) \quad 4.5(3.6, \mathrm{NE})$

8/13 (61.5)

$13.6(4.1, \mathrm{NE}) \quad 7.5(1.9,18.5)$

$5 / 8(62.5)$

NE $(7.4, \mathrm{NE}) \quad 10.9(2.3,19.1)$

In favor of 

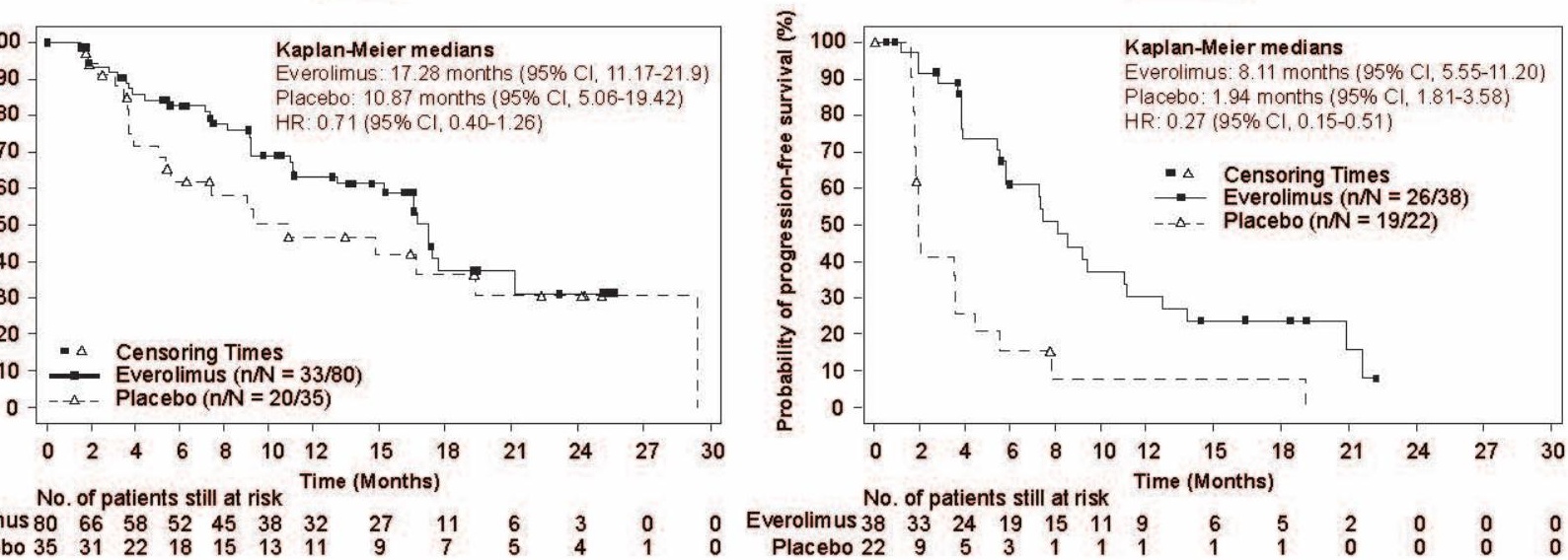

$\begin{array}{rllllllllllll}\text { Everolimus } 80 & 66 & 58 & 52 & 45 & 38 & 32 & 27 & 11 & 6 & 3 & 0 & 0 \\ \text { Placebo } 35 & 31 & 22 & 18 & 15 & 13 & 11 & 9 & 7 & 5 & 4 & 1 & 0\end{array}$

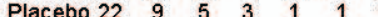

\section{Prior-SSA}

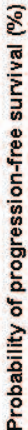
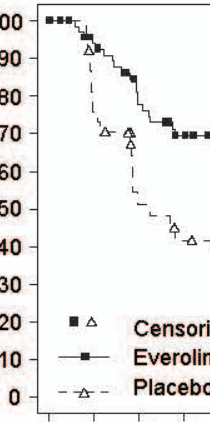

\section{Kaplan-Meier me dians}

Everolimus: 11.20 months $(95 \% \mathrm{Cl}, 9.20-17.28)$

Placebo :4.47 months ( $95 \% \mathrm{Cl}, 3.58-9.03$ )

HR: $0.54(95 \% \mathrm{Cl}, 0.32-0.89)$

$\triangle \Delta$

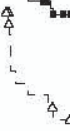

\section{Censoring Times}

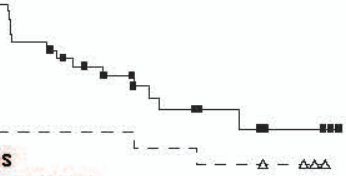

Everolimus $(\mathrm{n} / \mathrm{N}=37 / 77)$

$\triangle-$ Placebo $(n / N=26 / 38)$

$\begin{array}{lllllllllllll}0 & 2 & 4 & 6 & 8 & 10 & 12 & 15 & 18 & 21 & 24 & 27 & 30\end{array}$

No. of patients still at risk Time (Months)

Placebo 38 $\begin{array}{lllllllll}77 & 61 & 47 & 38 & 33 & 30 & 24 & 18 & 10\end{array}$

$\begin{array}{llllllll}38 & 28 & 16 & 12 & 8 & 6 & 6 & 6\end{array}$

D

Ne Prior-SSA

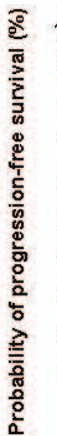

- $\triangle$ Censoring Times

$\rightarrow$ Everolimus $(\mathrm{n} / \mathrm{N}=33 / 64)$

Kaplan-Meier medians

Everolimus: 16.59 months ( $95 \% \mathrm{Cl}, 9.17-20.93$ )

Placebo: 7.52 months $(95 \% \mathrm{Cl}, 3.06-18.46)$

HR: $0.60(95 \% \mathrm{Cl}, 0.34-1.05)$

$-\triangle$ Placebo $(n / N=21 / 32)$

0

$\begin{array}{lllllllll}0 & 2 & 4 & 6 & 8 & 10 & 12 & 15 & 18\end{array}$

No. of patients still at risk Time (Months) $\begin{array}{lllllllll}64 & 56 & 50 & 46 & 37 & 29 & 25 & 21 & 8\end{array}$

$\begin{array}{llllllllll}\text { Placebo } & 32 & 22 & 16 & 13 & 11 & 10 & 8 & 6 & 5\end{array}$ 